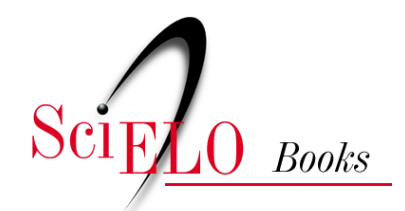

\title{
Histórias do Dr. Sebastião José de Oliveira (junho de 1999)
}

\author{
Virgínia Schall
}

\section{SciELO Books / SciELO Livros / SciELO Libros}

SCHALL, V. Histórias do Dr. Sebastião José de Oliveira (junho de 1999). In: Contos de Fatos: histórias de Manguinhos [online]. Rio de Janeiro: Editora FIOCRUZ, 2001, pp. 141-152. ISBN: 97885-7541-614-3. Available from: doi: 10.7476/9788575416143.0013. Also available in ePUB from: http://books.scielo.org/id/hdq6f/epub/schall-9788575416143.epub.

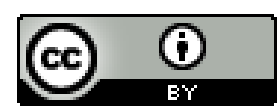

All the contents of this work, except where otherwise noted, is licensed under a Creative Commons Attribution $\underline{4.0 \text { International license. }}$

Todo o conteúdo deste trabalho, exceto quando houver ressalva, é publicado sob a licença Creative Commons Atribição 4.0. 


\title{
Histórias do Dr. Sebastião José de Oliveira (junho de 1999)
}

\author{
Oorganismo unicelularmaissimpleséuma máquina \\ mais complexa do que o mais refinado relógio de bolso. \\ Carl Sagan
}

E ncontrei o Dr. Sebastião em seu laboratório no segundo andar do parecendo fazer desenhos, possivelmente de uma nova espécie de inseto. Eu já havia escutado, em conversas informais, alguns trechos de algumas das histórias aqui incluídas, e sempre ficava admirada com o conhecimento do Dr. Sebastião sobre os grupos de insetos a que ele dedicou sua vida de pesquisador. Eram verdadeiras sutilezas de um mundo oculto para os demais e que nos desvendam as maravilhas e a diversidade infinita da natureza. Assim, nas poucas horas em que conversei com ele, pude reforçar a minha crença de que, por mais árduo que seja o trabalho de pesquisa - o qual por vezes obriga o pesquisador a passar horas em situações as mais desconfortáveis e repetir uma observação não se sabe quantas vezes -, quando há aquela motivação intrínseca e a curiosidade por desvendar aspectos deste cenário em que estamos imersos, ele será sempre lúdico, prazeroso e trará contribuições e novidades. E isso se reflete em sua fala, sempre acompanhada de um brilho no olhar e um entusiasmo contagiante, nos fazendo querer ouvir infinitamente. Espero então, provocar aqui o interesse que senti e passo agora a relatar. 


\section{Lição do Berne}

Esta história se passou em Joinville, Santa Catarina, uma dentre as muitas cidades que solicitavam os serviços do Dr. Sebastião, entomologista reconhecido nacional e internacionalmente pelo seu trabalho desenvolvido na Fiocruz. Após ter sido um dos pesquisadores da Fiocruz injustamente cassados pelo AI-5 e impedidos de continuar trabalhando na instituição, Dr. Sebastião, como relata, costumava ganhar a vida matando os borrachudos. Naquela ocasião, havia sido chamado a Joinville para implantar uma estratégia de controle dos borrachudos da região. Em Joinville, há vários rios e várias espécies de borrachudos, os quais usam as águas para colocar seus ovos, onde suas larvas se desenvolvem até se transformarem em adultos alados. Conhecedor dos simulídeos, insetos hematófagos que apresentam cerca de oitenta espécies no Brasil, sabia que em Joinville existia a mais importante espécie do gênero, comum no litoral leste do país, denominada cientificamente de Simulium pertinax. Em Joinville não havia apenas esta; outras espécies também podiam ser encontradas na área.

$\mathrm{Na}$ cidade, um órgão da prefeitura, a Fundação 25 de Julho, era responsável, entre outras coisas, pelo controle dos borrachudos. O diretor da fundação recebeu o Dr. Sebastião, relatou as suas dificuldades no controle e o acompanhou na inspeção dos rios. Tomaram o carro da prefeitura, que era dirigido por um auxiliar do próprio diretor. Seguiram para a área rural e, ao passarem próximo ao pasto de uma fazenda, Dr. Sebastião percebeu que diversas vacas mestiças holandesas estavam parasitadas pelo berne - que nada mais é do que a larva da mosca Dermatobiahominis, da família Oestridae, velha conhecida do pesquisador. Esta larva, ou berne, costuma ficar embaixo do couro do animal; é possível encontrar até dez bernes juntos, formando placas que podem originar uma grande ferida. Trata-se de um problema sério de saúde veterinária que afeta a pecuária. A afecção causada pela presença do berne é chamada de miíase. Dr. Sebastião não se conteve e falou quase que para si mesmo: "Engraçado, eu não sabia que tinha berne aqui em Joinville. 
Se eu tivesse mais tempo, ia amarrar um cavalo embaixo daquela árvore para pegar as moscas com os ovos da mosca do berne".

Eis o seu relato: "Quando falei isso, senti que o rapaz que dirigia o carro olhou para $\mathrm{o}$ agrônomo sem entender. Então eu perguntei a ele: sabe como é a transmissão do berne? Não? Pois eu vou te contar: a mosca do berne, que é azulada, pesadona, voa mal. Ela precisa do boi para completar o seu ciclo de vida. Como larva, sobrevive embaixo da pele do boi durante cerca de um mês, o que caracteriza o berne. Após este tempo, ela sai do interior da pele do animal, cai no chão, se enterra como pupa e ali fica de quarenta a cinqüenta dias. Portanto, sua vida dura aproximadamente três meses nesses dois estágios (dentro da pele do boi, como larva, e enterrada no solo, como pupa). Num dado momento, saem os adultos, sejam machos ou fêmeas. $\mathrm{O}$ curioso é que ambos não têm boca na fase adulta, se alimentam apenas na fase de berne. Os machos vão logo em busca de uma fêmea, copulam e depois morrem. As fêmeas vivem um pouco mais, até porem os ovos. Assim, para garantir a sua reprodução, capturam uma outra mosca durante o vôo e põem os ovọs colados no abdômen da mosca ou dos mosquitos capturados. $\mathrm{Na}$ mosca 'barriga de aluguel', os ovos ficam cimentados e embrionam. Quando essa mosca pousa num animal para lamber o suor ou o exsudato proveniente de locais da pele do boi onde já existem bernes, a larva, que está no interior do ovo, abre a tampa que existe na extremidade externa (a qual não fica colada na mosca). A larva, então, sai do ovo, desce por um pêlo e penetra na pele do animal. Se por acaso não houver tempo para ela sair do ovo (se houver um movimento brusco, se o animal bater com a cauda, ou como no caso de um eqüino, que faz movimentos convulsivos permanentes na pele), ela se recolhe novamente para o interior, quando a tampa se fecha automaticamente, e a larva fica aguardando uma nova oportunidade. As moscas mais comumente capturadas pela Dermatobia são as lambedoras de suor dos animais, nas quais ela deposita entre 10 e 15 ovos. Como a fêmea põe cerca de duzentos ovos no total, ela precisa capturar umas dez moscas ou mosquitos para fazer a postura". 
Dr. Sebastião comenta: "Eu já apanhei moscas lambedoras do suor com posturas dos dois lados do abdômen ou sobrepostas, o que atesta que elas haviam sido capturadas duas ou mais vezes pela mosca do berne. Essa mosca vai ser a portadora do berne e, ao pousar sobre o boi, o transmite". Representando com a própria mão a forma do ovo, Dr. Sebastião o descreve: comprido e com um opérculo numa das extremidades. Cita o trabalho publicado em $1917^{36}$ pelos pesquisadores Artur Neiva e J. Florêncio Gomes, os quais fizeram uma descrição completa da biologia da mosca do berne, incluindo todos os seus estágios. Pois bem, cada ovo fica ali no abdômen da mosca até a larva penetrar na pele do boi, como já descrito. É interessante observar que os bernes estão, em geral, em regiões não alcançadas pela cauda do boi. Ainda que a mosca transportadora dos ovos morra, os ovos continuam viáveis por 15 dias. Dr. Sebastião conta que quando levava para os laboratórios as moscas coletadas no campo contendo ovos no abdômen e espetava alguma mosca morta no alfinete entomológico, bastava um sopro para que o hálito quente provocasse a saída da larva, a qual se orienta pelo calor, de dentro do ovo. Ao sentir o calor do corpo do boi, ela sai do ovo e entra pela base do pêlo. Como os pêlos são longos (em relação ao tamanho das moscas), raramente elas atingem a pele do animal; por isso a larva, quando consegue sair do ovo, desce pelo pêlo até atingir sua base e então alcançar a pele, perfurá-la e entrar. No caso do cavalo e de outros eqüídeos, o tremor não impede a entrada da larva, mas sim que a larva tenha tempo para sair do ovo.

A melhor maneira de coletar a mosca transportadora é escolher uma grande árvore copada, porque no calor o gado é atraído para a sua sombra, e, então, amarrar em seu tronco um cavalo escuro, que contrasta com a cor dos ovos dos insetos. A mosca do berne fica no tronco ou nas copas das

\footnotetext{
36 NEIVA, A. \& GOMES, J. F. Biologia da mosca do berne (Dermatobia bominis) observada em todas as suas fases, Anais Paulistas de Medicina e Cirurgia, 8(9): 197-309, 1917.
} 
árvores sob as quais estão os bois. $\mathrm{O}$ alvo delas são justamente as outras moscas que estão lambendo o suor dos animais. São três as moscas lambedoras mais comuns que se prestam a ser transportadoras de ovos $\mathrm{da}$ mosca do berne. Uma outra espécie, a Neizomyia lutzi, é a mais rara; sendo hematófaga, suga o sangue do gado. Para capturar as moscas, o entomologista precisa ter uma rede apropriada, ficar observando e aproveitar o momento propício. A mosca do berne, a Dermatobia, por sua vez, é grande e azulada e tem um vôo pesado, semelhante ao das abelhas mangangás, sendo difícil capturá-la. Dr. Sebastião conta que costumava capturá-las na Fazendinha no início da Serra das Agulhas Negras, na região de Penedo.

Continuando a história: no dia seguinte, o motorista que escutara aquela explicação minuciosa sobre a mosca do berne e o diretor da fundação foram buscar o Dr. Sebastião para levá-lo ao aeroporto. No caminho, o diretor disse ao motorista: "Conta aí o que você acabou de me dizer". O motorista, que era uma pessoa nativa da região, contou: "Pois é, doutor, ontem eu reuni a minha família no jantar e contei a todos o que aprendi sobre a mosca do berne. Ficou todo mundo interessado. Se o seu cachê não fosse tão alto, eu traria o senhor aqui na escola para fazer uma palestra para a meninada saber essas coisas tão interessantes que tão acontecendo aqui do lado delas e ninguém nem desconfia". Dr. Sebastião prometeu falar na escola em sua nova visita e comenta como esta história revela o quanto a educação está alienada da realidade local.

Contou ainda fatos interessantes, como o que aconteceu a um dos examinadores de sua tese de doutorado, um entomologista alemão, Dr. Ernest Josef Fittkau. Em visita ao Rio, decidiu ir até Valença com um amigo, visitando áreas rurais. Logo que retornou à Alemanha, saiu de férias e foi para a Itália a passeio. Lá, começou a sentir uma coisa estranha no couro cabeludo; logo descobriu que era um berne. Também a atriz Zezé Motta, amiga do Dr. Sebastião, estava gravando o filme Quilombo em Xerém quando surgiram dois calombos estranhos em sua coxa. Consultando o amigo, não foi difícil diagnosticar: berne. Como descreve Dr. Sebastião, o 
berne cresce e, junto, crescem uns espinhos de tamanhos variados que formam círculos em volta do corpo da larva. Também se desenvolvem os opérculos respiratórios (conhecidos popularmente como olhos do berne), que são dois e escuros. Quando a larva penetra na pele dos animais e do homem, ela vai crescendo e se dirigindo cada vez mais para o interior, deixando um furo na pele para que possa respirar. À medida que cresce, o furo fica maior, e como a larva penetra na pele verticalmente, o que aparece no buraco da pele são os opérculos, pretos, que ficam na parte posterior da larva. Daí vem a denominação de olhos de berne, certamente imprópria, mas fruto da imaginação popular, pela semelhança. Quando se tapa o buraco com esparadrapo, a larva ou berne não consegue respirare morre, podendo se tornar um foco de infecções. $\mathrm{O}$ nosso homem do interior tem duas maneiras de combater o berne: usando um extrato de fumo de rolo, que mata o berne (mas é necessário retirá-lo logo, para não infeccionar o local), ou, solução mais criativa, colocando sobre o buraco um pedaço de toucinho, de preferência fumeiro. $\mathrm{O}$ que acontece? $\mathrm{O}$ berne, impedido de respirar pelos seus próprios opérculos, faz uma reviravolta em seu corpo, para penetrar no toucinho até arranjar uma maneira de respirar de novo. Nessa reviravolta os espinhos de seu corpo dilaceram o tecido, já traumatizado pela invasão do próprio berne. Uma vez que a larva entra no toucinho, é só removê-lo junto com o berne. Dr. Sebastião comenta: é claro que o povo acha que o berne 'gosta' de toucinho, mas esta é outra história...

Essa descrição acurada e interessante, assim traduzida, certamente está ao alcance da compreensão do leigo, sendo útil na prevenção, no controle e no tratamento do berne. Além disso, é um exemplo de um belo fenômeno biológico, que demonstra as estratégias da natureza e da vida, e como vários animais estão reunidos em cadeias de sobrevivência, associados de maneiras as mais curiosas. No mundo dos insetos, há fenômenos e fenômenos que nos deixam perplexos, tamanha a sutileza que apresentam. Assim é que, nas demais histórias, poderemos vislumbrar outras curiosidades detalhadamente estudadas e vividamente descritas pelo Dr. Sebastião. 


\section{Entre Formigas e Moscas}

Esta é uma experiência rara, vivida pelo Dr. Sebastião com o seu mestre, orientador e amigo, o Dr. Hugo Souza Lopes, pesquisador com quem tive o privilégio de conviver durante alguns anos no Departamento de Biologia do IOC e que me também me contou uma bela história, incluída neste livro.

Dr. Sebastião costumava ir com o Dr. Hugo fazer coletas de insetos na represa do Grajaú, um lugar descrito com exuberância por Dr. Hugo, seu recanto predileto, próximo à sua casa, para onde costumava ir caminhando. ${ }^{37}$ Dr. Sebastião conta que era ainda estudante quando os dois puderam presenciar um fenômeno raro: uma correição de formigas, uma verdadeira passeata que costuma reunir mais de uma espécie. Em geral, essas formigas não têm ninhos fixos, vivem na mata ou em capoeiras e, num dado momento da vida, migram para outros lugares, onde vão construir uma nova morada. A correição é um pelotão de milhares de formigas e pode atingir até 10 metros de largura por 30 de comprimento, não em forma retangular exata, mas alargando-se e estreitando-se de acordo com os obstáculos do terreno. Em sua passagem, ao caminharem sobre as folhas secas, caídas ao solo, as formigas vão fazendo um barulhinho. Vão carregando alimentos para o próximo ninho e em seu caminho afugentam os demais insetos terrestres, como gafanhotos, baratas, grilos etc., e até pererecas pequenas, os quais saem em disparada para não serem atropelados pelo numeroso exército. A cena é deveras fantástica: uma larga coluna marchando em movimento, como uma gigantesca mancha, e, na frente, os animais fugindo. Para um entomologista, a correição de formigas tem um interesse especial. Como bom observador, esse especialista é capaz de perceber uma outra cena acontecendo na linha de frente da coluna, onde estão os animais a correr.

${ }^{37}$ O relato feito por Dr. Sebastião sobre esta experiência está incluído na história do Dr. Hugo. 
Acima deles, pode-se ver umas mosquinhas voando a uma altura entre 80 centímetros e 1 metro. São da famíliạ Conopidae, do gênero Stylogaster, e têm um abdômen longo, em forma de estilete. O que essas moscas fazem? Bem, as suas larvas vivern parasitando ortópteros como baratas, bichospau, louva-a-deus, gafanhotos, grilos, esperanças etc. Assim, a fêmea precisa depositar o ovo no abdômen de um ortóptero. O ovo da mosca tem um espinho na ponta, o qual pode ser espetado e fixado no outro inseto a ser parasitado. Desse modo, quando a mosca vê que um animal escapa das formigas, ela dá um mergulho e injeta o ovo entre dois segmentos de seu abdômen. Neste local, o ovo se desenvolve até larva, a qual cai na terra e se transforma em pupa, prosseguindo então o seu ciclo.

Dr. Hugo descreveu várias espécies dessas moscas. E Dr. Sebastião continua: "Em 1942 ou 43, deparei-me com uma correição em Teófilo Otoni, e coletei uma espécie nova, que foi descrita pelo Dr. Hugo. Depois, só pude ver outra durante a construção de Brasília. É uma lembrança mágica, a coluna em onda avançando pelo chão e os sons - tric-tec-tac - entremeados pelos barulhos dos outros animais maiores pulando na frente". São momentos inesquecíveis, cenas ocultas da natureza que encantam aqueles que amam observá-la.

\section{Quironomídeos Orixás}

O Dr. Sebastião é um dos maiores especialistas no mundo em quironomídeos, espécie de mosquitos parentes dos culicídeos; estes últimos são hematófagos de importância médica, por incluírem espécies transmissoras de doenças como a malária, a dengue e a febre amarela, filarioses e outras arboviroses. Os quironomídeos são biomonitores das águas, indicadores $\mathrm{da}$ sua qualidade. Os quiromomídeos marinhos vivem nos costões batidos pela água do mar, locais onde o Dr. Sebastião, que já descreveu seis novas espécies, costuma fazer as suas coletas. São insetos curiosos, de comportamento peculiar. 
Seu nome vem da palavra grega cheironomia, quironomia, que significa mímica, ou a arte de associar os gestos ao discurso, à representação teatral ou à dança. $\mathrm{E}$, como conta Dr. Sebastião, algumas espécies se acasalam no ar, uma dança nupcial efêmera mas eficiente para garantir a sua descendência e perpetuar a vida. As seis espécies descritas pelo Dr. Sebastião receberam nomes científicos muito especiais, como, por exemplo, Thalassomyaoshum e Thalassomyayemanja. Como explicou, é comum que os taxionomistas usem nomes gregos, como o próprio nome Thalassomya, derivado de Thalassos, mar, oceano, usado para designar o inseto como 'mosca do mar'. Dr. Sebastião acrescenta que há um outro gênero, que ele ainda não achou no Brasil, o Thethymyia, isto é, 'mosca da deusa do mar'. A deusa Thetis era a Iemanjá dos gregos. Assim, Dr. Sebastião decidiu homenagear as divindades africanas, denominando as novas espécies com nomes de orixás. As outras quatro espécies são: Telmatogeton eshu, T. oshosse, T. shango e T. oshala, as quais estão descritas em sua tese de doutorado. ${ }^{38}$ Segundo Dr. Sebastião, embora os nomes não tenham relação com as características morfológicas, em uma das espécies, T. shango, que se refere a Xangô, divindade que tem como ferramenta um machado duplo, observa-se esta forma nitidamente tanto no hipogígio do macho como na genitália da fêmea. Entretanto, Dr. Sebastião esclarece que foi apenas coincidência e explica que, na tese, apresenta a etimologia de cada nome, os quais foram grafados em minúscula, de acordo com as regras internacionais de nomenclatura zoológica, sem sinais gráficos, e escritos em iorubá: ebbu (Exu), oshala (Oxalâ), oshosse (Oxossi), yemanja (Iemanjá), oshum (Oxum) e shango (Xangô). Explica ainda que a única regra seguida na tese é que o primeiro orixá homenageado deveria ser Exu (esbu), pois nada se faz no candomblé sem agradar e agradecer a este orixá. Exu, além de ser o elo entre todos os orixás, é também aquele que abre e é dono dos caminhos do mundo.

${ }^{38}$ OLIVEIRA, S. J. Contribuição ao Conhecimentodos Chironomidae Marinhos (Insecta, Diptera) do Litoral
Brasileiro, 1998. Tese de Doutorado, Rio de Janeiro: IOC, Fiocruz. 
A coleta desses insetos já rendeu ao Dr. Sebastião momentos especiais e algumas situações esdrúxulas. Por exemplo: um dos lugares onde coletou e encontrou duas novas espécies (T. oshossee T.shango) é a Praia do Arpoador, no Rio de Janeiro. Normalmente, é preciso ir numa hora de maré baixa, com as rochas descobertas, e não é raro chamar a atenção das pessoas, que não entendem o que faz ali um homem tão atento às pedras das encostas. Certa vez, ficou em São Paulo e decidiu ir a Santos. No sábado foi até São Vicente, onde há um monumento a Martim Afonso de Souza. A praia estava lotada e, assim que a maré baixou, Dr. Sebastião pegou os seus vidrinhos de coleta e se aproximou das rochas. É preciso colar o rosto às pedras, pois as larvas, pupas e adultos são da mesma cor, e o olho tem de ir se acostumando devagar até distingui-las. Tratava-se de uma investigação que poderia resultar, e resultou, na descrição de uma espécie nova. Tão absorto estava que se esqueceu do público, grupos de pessoas já intrigadas com o seu estranho comportamento. Um homem se aproximou e disse: "Vi o senhor acariciando a pedra e fiquei pensando: 'Será um maluco?" Mas, ao me aproximar, percebi que o senhor tem uns vidrinhos. O que tem aí? São bichinhos? Pode mostrar à minha noiva?" Bastou isso e logo Dr. Sebastião se viu cercado por uma pequena multidão curiosa.

Existem quironomídeos marinhos do gênero Pontomyia que são encontrados nos costões das praias da Costa Rica. Tanto a larva quanto a pupa e a fêmea estão entre quarenta e cinqüenta metros abaixo do nível da água. A fêmea é vermiforme e não voa. O macho tem a asa em forma de remo, e a usa como tal. Ele mergulha até encontrar a fêmea para copular. Traz a fêmea para a superfície, para que ela ponha os ovos no solo. Este é um momento fugaz para a fêmea, que tem uma forma rudimentar e, assim que faz a postura dos ovos, morre. Uma outra espécie, Clunio brasiliensis, descrita por Oliveira em 1950, também apresenta um comportamento semelhante ao dos mosquitos da Costa Rica. O macho é alado e a fêmea não tem asas. Estas ficam nas pedras, entre as algas. Quando o macho vê a fêmea, ele desce, carrega a fêmea, voa a uma altura 
de 2 a 3 metros copulando, e depois pousa no mesmo local para que a fêmea ponha os ovos. Dr. Sebastião descreve o vôo nupcial dos mosquitos ao entardecer na Praia do Farol em Salvador, uma dança curta que termina com a morte dos parceiros depois de garantida a continuidade da vida, presente nos ovos órfãos que repetirão milenarmente o ciclo. No Japão há também uma outra espécie. A fêmea é incapaz de sair da pupa. Então o macho desce, rasga a pupa da fêmea e a carrega para copular; depois a devolve ao solo para pôr os ovos. Essas fêmeas não têm boca e também morrem após a postura.

Há outras espécies que vivem em áreas mais internas. Os insetos adultos costumam ser atraídos pela luz. À noite, as vitrines de Copacabana ficam cheias deles. Assim, Dr. Sebastião costumava ir até lá para coletá-los. Numa certa ocasião, na década de 50, estava em Belo Horizonte e decidiu coletar os mosquitos nas vitrines do Edifício Sul-América. Olhava para um lado, para outro e, quando não via ninguém, aproximava o vidrinho da vitrine e prendia alguns. Era uma loja do tipo relojoaria. De repente, um guarda segurou o seu braço e falou: está preso! O interessante foi que, depois de mostrar os vidrinhos e explicar o que fazia ao guarda, este acabou cooperando, vigiando a rua e avisando quando vinha gente.

Uma outra vez, Dr. Herman Lent pediu ao Dr. Sebastião, que estava indo para o Ceará, que coletasse uma espécie de barbeiro que existe no interior do município de Russas, um pequeno povoado. Dr. Sebastião começou a procurar os barbeiros nos casebres e nada encontrou durante o dia. À noite, resolveu retornar aos casebres para ver se o horário poderia favorecer a sua busca. Como relata, "fui e encontrei duas senhoras de cócoras, com as costas na parede do casebre, trançando chapéu de palha de carnaúba, com muita habilidade. A iluminação provinha de uma lamparina de óleo de carrapato, nome dado ao óleo de mamona. Comecei a conversar com elas. Acostumei-me com a luz e pude perceber que os barbeiros saíam da parede e começavam a picar as senhoras. Perguntei a elas: por que as senhoras não matam os bichos? Uma delas respondeu: 
porque são criaturas de Deus. Foi nessa hora que encontrei os barbeiros e ainda pude ter uma amostra de como as crenças e a falta de informação favorecem a permanência de muitos males em nosso país". 


\section{Sebastião José de Oliveira ${ }^{39}$}

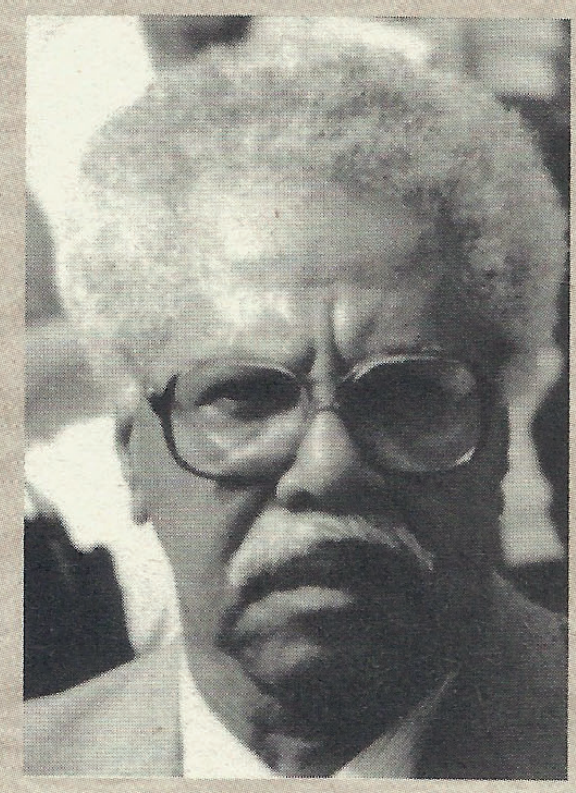

Dr. Sebastião José de Oliveira nasceu em 3 de novembro de 1918 no Rio de Janeiro. Formou-se em medicina veterinária na Escola Nacional de Veterinária, hoje Universidade Federal Rural do Rio de Janeiro. É pesquisador titular da Fiocruz, onde ingressou em 1939, tendo sido cassado pelo Al-5 em 1970, no episódio conhecido como Massacre de Manguinhos, e reintegrado em 1986. Atualmente é - curador da coleção Entomológica do IOC. É professor de zoologia, parasitologia e entomologia em cursos de formação profissional e pós-graduação na Escola Nacional de Veterinária e no IOC. Publicou cerca de 95 trabalhos científicos e de divulgação científica e é responsável pela descrição de setenta novas espécies de insetos e de quatro gêneros: Lopescladius, Brasixenos, corytibacladius e Laurotanypus. Um gênero, Oliveiriella, e dez espécies de insetos, descritos por outros pesquisadores, receberam o nome de oliveirai em homenagem à sua contribuição à ciência. Desenvolveu estudos sobre inseticidas e controle de pragas. Publicou em co-autoria com o Dr. Herman Lent, o primeiro trabalho brasileiro sobre combate ao barbeiro com DDT. Participou de cerca de cinqüenta congressos nacionais e internacionais, em alguns dos quais foi o único representante da América do Sul. Recebeu diversos prêmios, como o Estácio de sá (Ciência) do

\footnotetext{
${ }^{39}$ Biografia extraída do curriculum vitae resumido do pesquisador.
} 
governo do estado do Rio de Janeiro, em 1985, e o Prêmio Zumbi, da Associação Nacional de Defesa dos Direitos do Negro, em 1988. Em 1995 recebeu a Medalha Tiradentes da Assembléia Legislativa do Estado do Rio de Janeiro. Foi também subsecretário de Ciência e Tecnologia do governo do estado do Rio de Janeiro em 1992 (gestão Leonel Brizola). Em 1998, aos oitenta anos, defendeu a tese contribuição ao Conhecimento dos Chironomidae Marinhos (Insecta, Diptera) do Litoral Brasileiro, com a qual obteve o grau de doutor em ciências (entomologia) no curso de pós-graduação em biologia parasitária do IOC. Foi sócio fundador da Sociedade Brasileira de Zoologia, membro da Royal Entomological Society, de Londres, da Sociedade Brasileira de Entomologia, de Medicina Veterinária e de Parasitologia e da Fundação Brasileira para a conservação da Natureza. 